\title{
Development of a Loop-Mediated Isothermal Amplification Assay for the Detection of Dickeya spp.
}

\author{
Jarred Yasuhara-Bell, Glorimar Marrero, Mohammad Arif, Asoka de Silva, and Anne M. Alvarez†
}

First author: Department of Molecular Biosciences and Bioengineering, and second, third, fourth, and fifth authors: Department of Plant and Environmental Protection Sciences, University of Hawai'i at Mānoa, Honolulu 96822. Accepted for publication 10 July 2017.

\begin{abstract}
Dickeya and Pectobacterium spp. are responsible for soft-rotting diseases of several plant species, some with overlapping host range. On potato, symptoms caused by these pathogens cannot be clearly differentiated. Disease results in the downgrading and rejection of potato seed, thus requiring additional phytosanitary restrictions across Northern Europe and other parts of the world. In an effort to provide a more timely and accurate diagnostic to distinguish these two groups of pathogens, a method for detecting Dickeya spp. using loop-mediated isothermal amplification (LAMP) was developed.

The LAMP assay can be used to test crude extracts prepared directly from symptomatic lesions. The entire test can be completed in less than $30 \mathrm{~min}$, making it faster than the current diagnostic standard, the pelADE conventional polymerase chain reaction. Additionally, the LAMP assay was able to detect Dickeya DNA in samples spiked with varying amounts of Pectobacterium DNA, thus demonstrating the highly specific and sensitive nature of the assay, which can be applied on survey samples with mixed soft-rotting bacterial populations.
\end{abstract}

World-wide, Dickeya and Pectobacterium are important genera containing several species of plant-pathogenic bacteria that are responsible for soft-rotting diseases on a variety of plant crops, including potato, maize, tomato, pineapple, sugar beet, rice, and banana, as well as many ornamental plants (Gardan et al. 2003; Ma et al. 2007; Samson et al. 2005). In global potato production, Pectobacterium carotovorum and P. atrosepticum have dominated the pathogenic populations observed on potato plants affected with blackleg and soft rot; other species of Pectobacterium have recently been reported in many of the potato-growing regions of the world (Pritchard et al. 2016). In temperate regions, $P$. carotovorum, P. atrosepticum, and Dickeya dianthicola, the latter of which has been detected in potato fields in Europe since the 1970s, pose significant production constraints to the potato industry. Furthermore, D. solani, a recently described pathogen (van der Wolf et al. 2014b), has emerged as an additional threat to potato production in Europe (Toth et al. 2011), whereas D. dadantii and D. zeae are known to cause diseases in potato stems and tubers in tropical and subtropical regions of the world (Ngadze et al. 2010; Samson et al. 2005).

Damage caused by pests and pathogens plays a significant role in crop losses throughout the world. New outbreaks of blackleg and soft-rot diseases are thought to be the result of movement of latently infected planting material, which has also been attributed to the worldwide distribution of Pectobacterium and Dickeya spp. Efforts to curtail the spread of these pathogens has prompted legislation such as the zero tolerance policy for all Dickeya spp. enacted by Scotland to protect its market on the export of "clean" seed for potato production (Pritchard et al. 2016). However, it should be noted that tolerance for blackleg in European seed-potato tubers differs from country to country (Toth et al. 2011). Therefore, diagnostic tests in support of legislation should be reliable and accurate, and able to discriminate between Pectobacterium and Dickeya spp.,

†Corresponding author: A. Alvarez; E-mail: alvarez@hawaii.edu

The GenBank accession number for the $d n a A$ gene sequence used in this study was KY967613.

(C) 2017 The American Phytopathological Society because efficient detection of these pathogens in plant material, or exclusion thereof, is necessary for timely implementation of eradication or containment measures to prevent or limit spread of these pathogens.

Currently, diagnostic testing for the detection and identification of Pectobacterium and Dickeya spp. has depended on the isolation of viable bacterial cells on semiselective crystal-violet pectate (CVP) culture medium, followed by biochemical analyses and the use of more sensitive conventional polymerase chain reaction (PCR) or species-specific real-time PCR. However, validated species-specific real-time PCR assays do not exist for all species of Pectobacterium or Dickeya (Czajkowski et al. 2015; Humphris et al. 2015). The drawback to current diagnostic testing methods is the need for hightech facilities and equipment, as well as the associated costs of a skilled operator or diagnostician.

Molecular detection and differentiation techniques are more precise than classical and biochemical analyses and reduce the delay between sample collection and test results. In contrast to conventional PCR and real-time PCR, loop-mediated isothermal amplification (LAMP) is an amplification method that uses a Bst DNA polymerase with strand-displacement activity and two to three sets of primers to amplify DNA with high specificity under isothermal conditions in less than $1 \mathrm{~h}$ (Nagamine et al. 2001, 2002; Notomi et al. 2000). At present, LAMP assays have been developed for the detection of $P$. atrosepticum ( $\mathrm{Li}$ et al. 2011) and $P$. carotovorum (Yasuhara-Bell et al. 2016) but none for the detection of Dickeya spp. In this study, a LAMP assay for the rapid detection of Dickeya spp. was developed. The specificity of the LAMP assay was tested against Pectobacterium spp. and other plant-pathogenic bacteria associated with potato or overlapping hosts of the genus Dickeya. Results of further validation tests involving environmental samples of fieldgrown pineapple infected with Dickeya spp. and laboratory-inoculated potato, as well as spiked competition assays, are presented.

\section{MATERIALS AND METHODS}

Bacterial strains and DNA extraction. Strains of bacteria used in this study included the six plant-pathogenic species of Dickeya described currently in the literature, along with other plant-associated 
pathogens with overlapping hosts or genera known to be closely related to Dickeya (Table 1). Bacterial strains were grown on TZC medium (agar at $17 \mathrm{~g} / \mathrm{liter}$, peptone at $10 \mathrm{~g} / \mathrm{liter}$, glucose at $5 \mathrm{~g} / \mathrm{liter}$, and $0.001 \%$ 2,3,5-triphenyl-tetrazolium chloride) or TZC-S (substitute sucrose at $5 \mathrm{~g} /$ liter in place of glucose for Clavibacter spp.) and allowed to incubate at $26^{\circ} \mathrm{C}\left( \pm 2^{\circ} \mathrm{C}\right)$ until colony formation. Bacteria from single colonies were suspended in 0.75 to $1.0 \mathrm{ml}$ of sterile distilled water and thoroughly mixed by vigorous vortexing. Suspensions were heated to $95^{\circ} \mathrm{C}$ for $10 \mathrm{~min}$ on a digital heat block, allowing cell lysis and DNA release into suspension, then allowed to cool to room temperature or held overnight a $4^{\circ} \mathrm{C}$ before use as a template for LAMP testing. All suspensions were stored at $4^{\circ} \mathrm{C}$. The crude lysates were used in all LAMP assays, unless otherwise stated.

Primer design and LAMP protocol. The $m g l C$ gene, a $\beta$ methylgalactoside transporter, was chosen as the candidate target for primer design. The sequences of the target region in Dickeya spp., including D. dadantii (PRJNA30, PRJNA172906, and PRJNA172953) and subsp. dieffenbachiae (PRJNA172911), D. dianthicola (PRJNA172901, PRJNA173463, PRJNA172903, and PRJNA173395), D. chrysanthemi (PRJNA172904, PRJNA172902, PRJNA172952, and PRJNA31295), D. solani (PRJNA173464, PRJNA172958,
PRJNA172957, and PRJNA173396), D. zeae (PRJNA33667, PRJNA229184, PRJNA172951, PRJNA172883, PRJNA172907, PRJNA172950, and PRJNA172959), D. paradisiaca (PRJNA172954 and PRJNA33069), and Dickeya spp. PRJNA173398, PRJNA172910, PRJNA172949, and PRJNA172956, were obtained from the National Center for Biotechnology Information (NCBI) GenBank nucleotide database. Molecular Evolutionary Genetics Analysis (MEGA) version 4.0 (Tamura et al. 2007) was used to perform a multiple sequence alignment of the sequences, followed by sequence comparison with the Species Demarcation Tool version 1.2 (Muhire et al. 2014) using default parameters.

LAMP primers (Table 2) were designed using the primer design program PrimerExplorer V4 (Eiken Chemical Co., Ltd, Tokyo), available at http://primerexplorer.jp/e/. The LAMP reactions were performed with $5 \mu \mathrm{l}$ of primer mix, consisting of $\mathrm{MglC}-\mathrm{F} 3(0.2 \mu \mathrm{M})$, $\operatorname{MglC}-B 3(0.2 \mu \mathrm{M}), \operatorname{MglC}-F I P(1.6 \mu \mathrm{M}), \operatorname{MglC}-B I P(1.6 \mu \mathrm{M})$, MglC-Loop $(0.8 \mu \mathrm{M})$, MglC-Loop Probe $(0.08 \mu \mathrm{M})$, and Quencher Probe $(0.16 \mu \mathrm{M})$ (Kubota et al. 2011) per reaction; $15 \mu$ l of Isothermal Mastermix (OptiGene, Horsham, West Sussex, UK); and $5 \mu l$ of sample/template DNA. Positive and negative controls contained $5 \mu \mathrm{l}$ of $D$. dadantii (Collection Française de Bactéries Associées aux

TABLE 1. Bacterial strains and corresponding reaction results with loop-mediated isothermal amplification (LAMP) primers designed in this study

\begin{tabular}{|c|c|c|c|}
\hline Number ${ }^{\mathrm{a}}$ & Strain ID $^{\mathrm{b}}$ & Organism & LAMP \\
\hline A2431 & IRRI $1427-4$ & Acidovorax avenae & - \\
\hline A2432 & BCE-12 & A. avenae & - \\
\hline A2433 & CHY9NF & A. avenae & - \\
\hline A6168 & EluW3L16 & Brenneria spp. & - \\
\hline A6169 & Eni5D312 & Brenneria spp. & - \\
\hline A6170 & Equ11D3 & Brenneria spp. & - \\
\hline A6171 & ATCC 15712 & Brenneria salicis & - \\
\hline A1666 & ATCC 23060 & Burkholderia andropogonis & - \\
\hline A2058 & $\mathrm{H} 160$ & $\begin{array}{l}\text { Clavibacter michiganensis subsp. } \\
\text { michiganensis }\end{array}$ & - \\
\hline A6094 & NCPPB 2579; LMG 3698 & C. michiganensis subsp. nebraskensis & - \\
\hline A6095 & 20037 & C. michiganensis subsp. nebraskensis & - \\
\hline A6096 & 200800460 & C. michiganensis subsp. nebraskensis & - \\
\hline A2041 & $\mathrm{R} 8$ & C. michiganensis subsp. sepedonicus & - \\
\hline A5415 & CFBP $2048^{\mathrm{T}}$ & Dickeya chrysanthemi biovar chrysanthemi & + \\
\hline A6062 & CFBP 3701 & D. chrysanthemi biovar chrysanthemi & + \\
\hline A6063 & CFBP 3262 & D. chrysanthemi biovar chrysanthemi & + \\
\hline A5574 & IPO 2117 & D. chrysanthemi biovar parthenii & + \\
\hline A5641 & CFBP 1270 & D. chrysanthemi biovar parthenii & + \\
\hline A5416 & CFBP $1269^{\mathrm{T}}$ & D. dadantii subsp. dadantii & + \\
\hline A5642 & CFBP 3855 & D. dadantii subsp. dadantii & + \\
\hline A5643 & CFBP 6467 & D. dadantii subsp. dadantii & + \\
\hline A5419 & CFBP 2051 & D. dadantii subsp. dieffenbachiae & + \\
\hline A5578 & IPO 2124 & D. dadantii subsp. dieffenbachiae & + \\
\hline A5646 & CFBP 3694 & D. dadantii subsp. dieffenbachiae & + \\
\hline A6060 & CFBP 3698 & D. dadantii subsp. dieffenbachiae & + \\
\hline A6061 & CFBP 1247 & D. dadantii subsp. dieffenbachiae & + \\
\hline A5418 & CFBP $1200^{\mathrm{T}}$ & D. dianthicola & + \\
\hline A5571 & IPO 1741 & D. dianthicola & + \\
\hline A5644 & CFBP 2015 & D. dianthicola & + \\
\hline A5645 & CFBP 4155 & D. dianthicola & + \\
\hline A6058 & CFBP 1982 & D. dianthicola & + \\
\hline A6059 & CFBP 3706 & D. dianthicola & + \\
\hline A5420 & CFBP $4178^{\mathrm{T}}$ & Dickeya paradisiaca & + \\
\hline A5579 & IPO 2127 & D. paradisiaca & + \\
\hline A5688 & CFBP 3691 & D. paradisiaca & + \\
\hline A6064 & CFBP 3696 & D. paradisiaca & + \\
\hline A6065 & CFBP 1445 & D. paradisiaca & + \\
\hline A5581 & IPO 2187 & Dickeya solani & + \\
\hline A5582 & IPO 2188 & D. solani & + \\
\hline A5417 & CFBP 1278 & Dickeya sp. & + \\
\hline A5421 & CFBP 1272 & Dickeya sp. & + \\
\hline A6066 & CFBP 1889 & Dickeya sp. & + \\
\hline A6067 & CFBP 1890 & Dickeya sp. & + \\
\hline
\end{tabular}

(continued on next page)

a Acquisition number from the Alvarez laboratory at the University of Hawai'i at Mānoa

b ATCC, American Type Culture Collection, United States; CFBP, Collection Française de Bactéries Associées aux Plantes (French Collection for Plant-Associated Bacteria), France; IPO, Instituut voor Plantenziektenkundig onderzoek (Institute for Phytopathological Research), The Netherlands; LMG, Collection of the Laboratorium voor Microbiologie en Microbiele Genetica, Belgium; and NCPPB, National Collection of Plant Pathogenic Bacteria, United Kingdom. 
Plantes [CFBP] 2051) or D. chrysanthemi (CFBP 2048) DNA, and molecular-grade water or $P$. carotovorum subsp. carotovorum DNA, respectively. All reactions were performed in triplicate and analyzed using the iQ5 Multicolor Real-Time PCR Detection System (Bio-Rad, Hercules, CA) with the following parameters: $65^{\circ} \mathrm{C}$ for $30 \mathrm{~min}$ (could be extended to $40 \mathrm{~min}$ to an hour for low concentrations of DNA), with fluorescence readings being taken at 1-min intervals, and a final optional step of $2 \mathrm{~min}$ at $85^{\circ} \mathrm{C}$.

LAMP specificity analysis. To determine whether the primers were specific to Dickeya spp., extracted DNA from Pectobacterium spp., Clavibacter spp., Ralstonia solanacearum, Xanthomonas axonopodis pv. dieffenbachiae, and other plant-associated pathogens (Table 1) were tested. Each sample was loaded in triplicate with positive and negative controls, as described above.

LAMP sensitivity assay for Dickeya spp. The sensitivity of the LAMP assay was assessed with 10-fold serial dilutions of D. solani (IPO 2187) DNA from $5 \mathrm{ng} / \mu \mathrm{l}$ to $5 \mathrm{fg} / \mu \mathrm{l}$. Purified DNA was extracted using the Wizard Genomic DNA purification kit (Promega Corp., Madison, WI), followed by use of a NanoDrop Model ND-1000 (NanoDrop Technologies, Inc., Wilmington, DE) to quantify and adjust the starting dilution of DNA. LAMP assays were performed as described above.

Additionally, to assess the sensitivity of the LAMP assay, reactions were performed with spiked amounts of $P$. carotovorum subsp. carotovorum WPP14 (A6155) DNA in the presence of D. solani (IPO 2187) DNA, which was held constant at the detection limit of the LAMP assay ( $5 \mathrm{pg}$ ) or used at $1 \mathrm{ng} /$ reaction. Reactions were spiked with increasing amounts of $P$. carotovorum subsp. carotovorum DNA at a final concentration of $5,10,20$, or $100 \mathrm{ng} /$ sample, along with $D$. solani DNA at both $5 \mathrm{pg}$ and $1 \mathrm{ng} /$ reaction, totaling $5 \mu \mathrm{l}$. Additionally, a 1:1 mixture of $100 \mathrm{ng}$ of $D$. solani IPO 2187 DNA and P. carotovorum subsp. carotovorum WPP14 DNA was also assessed to check for inhibition of the LAMP reaction at high DNA concentrations. The following were used as negative controls: P. carotovorum subsp. carotovorum WPP14 DNA only at $1 \mathrm{ng}$, or molecular-grade water only; the positive control was $5 \mathrm{pg}$ or $1 \mathrm{ng}$ of $D$. solani IPO 2187 DNA only, corresponding to the amount included in the test sample. All tests were run in duplicate using the LAMP parameters described above.

Evaluation of LAMP for field application. LAMP was evaluated for field application via two separate in planta testing methods. First, samples of pineapple (Ananas comosus) showing symptoms of bacterial heart rot and a healthy-looking control were collected from the same field and row of a pineapple-growing field on Oahu, HI. Samples, one leaf each from an infected plant or healthy-looking control, were treated as described by Kaneshiro et al. (2008) for the isolation of Dickeya spp., except that the remaining volume of macerate was boiled at $95^{\circ} \mathrm{C}$ for $10 \mathrm{~min}$ in a digital heat block, allowed to cool and sediment overnight at $4{ }^{\circ} \mathrm{C}$, then used for testing with the LAMP assay. LAMP assays were performed in triplicate alongside a positive (D. chrysanthemi CFBP 2048) and nontemplate (sterile distilled water used in isolation

TABLE 1. (continued from preceding page)

\begin{tabular}{|c|c|c|c|}
\hline Number $^{\mathrm{a}}$ & Strain ID $^{b}$ & Organism & LAMP \\
\hline A6174 & & Dickeya sp. & + \\
\hline A5422 & CFBP $2052^{\mathrm{T}}$ & Dickeya zeae & + \\
\hline A5423 & CFBP 6466 & D. zeae & + \\
\hline A5647 & CFBP 1531 & D. zeae & + \\
\hline A6068 & CFBP 1533 & D. zeae & + \\
\hline A6069 & CFBP 1277 & D. zeae & + \\
\hline A6070 & CFBP 1884 & D. zeae & + \\
\hline A6071 & CFBP 1871 & D. zeae & + \\
\hline A6072 & CFBP 3804 & D. zeae & + \\
\hline A6073 & CFBP 1447 & D. zeae & + \\
\hline A6074 & CFBP 3707 & D. zeae & + \\
\hline A6075 & CFBP 1502 & D. zeae & + \\
\hline A3131 & ATCC 13048 & Enterobacter aerogenes & - \\
\hline A5149 & B193 & E. cloacae & - \\
\hline A6125 & S-3 & Klebsiella oxytoca & - \\
\hline A6133 & ATCC 13883 & K. pneumoniae & - \\
\hline A6126 & S-4 & K. variicola & - \\
\hline A6140 & $\mathrm{CC} 27$ & Pantoea agglomerans & - \\
\hline A6162 & Eca6 & Pectobacterium atrosepticum & - \\
\hline A6163 & Eca31 & P. atrosepticum & - \\
\hline A6164 & SCRI1043; BAA-672 & $P$. atrosepticum & - \\
\hline A6165 & Ecb1 & P. betavasculorum & - \\
\hline A6166 & Ecb2 & P. betavasculorum & - \\
\hline A6167 & Ecb6 & P. betavasculorum & - \\
\hline A6148 & WPP1 & P. carotovorum subsp. brasiliensis & - \\
\hline A6149 & WPP5 & P. carotovorum subsp. brasiliensis & - \\
\hline A6150 & WPP17 & P. carotovorum subsp. brasiliensis & - \\
\hline A6151 & WPP20 & P. carotovorum subsp. brasiliensis & - \\
\hline A6152 & WPP165 & P. carotovorum subsp. brasiliensis & - \\
\hline A6153 & WPP2 & P. carotovorum subsp. carotovorum & - \\
\hline A6154 & WPP12 & P. carotovorum subsp. carotovorum & - \\
\hline A6155 & WPP14 & P. carotovorum subsp. carotovorum & - \\
\hline A6156 & WPP16 & P. carotovorum subsp. carotovorum & - \\
\hline A6157 & WPP161 & Pectobacterium wasabiae & - \\
\hline A6158 & WPP163 & P. wasabiae & - \\
\hline A6159 & WPP168 & P. wasabiae & - \\
\hline A6160 & WPP172 & P. wasabiae & - \\
\hline A6161 & SCRI488 & P. wasabiae & - \\
\hline A3292 & CC95; GMI1000 & Ralstonia solanacearum & - \\
\hline A1965 & D6 & Xanthomonas axonopodis pv. dieffenbachiae & - \\
\hline A2046 & 1591 & $X$. axonopodis pv. dieffenbachiae & - \\
\hline A2108 & D78-3 & $X$. axonopodis pv. dieffenbachiae & - \\
\hline A5603 & V108LRUH1 & X. axonopodis pv. dieffenbachiae & - \\
\hline
\end{tabular}


procedure) control, as described above. From one of the infectedplant tissues, a single colony (strain A6174) (Table 1) producing indigoidine on TZC medium was isolated and used in colony PCR with pelADE (Nassar et al. 1996) and dnaA (Marrero et al. 2013; Schneider et al. 2011) primers, followed by sequencing of the latter marker.

Second, store-purchased potato (Solanum tuberosum) tubers $(n=$ 2) were stab inoculated in two distinct spots per sample using a sterile toothpick dipped in D. solani IPO 2187 suspended at an optical density at $600 \mathrm{~nm}\left(\mathrm{OD}_{\mathrm{A} 600}\right)$ of approximately 0.1 . Each potato was also inoculated with sterile distilled water to use as a negative control on each potato. An additional potato was also inoculated at three distinct spots with sterile distilled water to use as a negative control in this assay. Briefly, inoculated potato tubers were incubated in a sealed plastic container at high humidity for 2 days at room temperature to allow symptom development. Macerated tissue $\left(1 \mathrm{~cm}^{3}\right)$ or mock-inoculated tissue (stabbed with sterile distilled water) was excised with a sterile scalpel and transferred to a 1.5-ml Eppendorf tube containing $500 \mu \mathrm{l}$ of sterile distilled water. Bacteria were allowed to diffuse for $20 \mathrm{~min}$ before removal of the sampled tissue. The remaining suspension was then boiled at $95^{\circ} \mathrm{C}$ for $10 \mathrm{~min}$ in a digital heat block and allowed to cool to room temperature or held at $4^{\circ} \mathrm{C}$ for LAMP testing. Plant-sample suspensions were tested with the LAMP assay as described above, alongside a suspension of $D$. solani IPO $2187\left(\mathrm{OD}_{\mathrm{A} 600}=0.1\right)$ prepared the same way as the plant samples as positive control and sterile distilled water as a negative control.

PCR. PCR were performed using the pelADE (Nassar et al. 1996) and dnaA (Marrero et al. 2013; Schneider et al. 2011) primers, with PCR conditions performed as described previously. The obtained dnaA sequence was deposited into the GenBank database (KY967613) and used for phylogenetic analysis.

Phylogenetic analysis. Phylogenetic analysis of strain A6174 was performed using sequences obtained with the dnaA marker for species-level identification. Sequence alignment and phylogenetic analyses were performed using Geneious, version 10.0.5 (http:// www.geneious.com) (Kearse et al. 2012). The dnaA sequences for known strains were obtained from NCBI GenBank (Table 3). Sequences were aligned using ClustalW, taking into account the corresponding amino acid alignments for protein-coding genes. Neighbor-joining trees (Saitou and Nei 1987) were constructed using the Jukes-Cantor method (Jukes and Cantor 1969) to compute evolutionary distances. Confidence intervals were assessed using the bootstrap method with 1,000 replications (Felsenstein 1985).

\section{RESULTS}

Specificity of the Dickeya LAMP assay. LAMP primers were designed to detect the $m g l C$ gene, encoding a $\beta$-methlygalactoside transporter, after NCBI BLAST analysis revealed no homologous matches to closely related Pectobacterium spp. or low to no homology to other nontarget plant-associated pathogens. Sequence comparison of the full-length $\mathrm{mglC}$ gene illustrated that this gene had a percent identity between 84 and $100 \%$ (Fig. 1) among the
Dickeya spp. tested, therefore making it a good candidate for primer design. Primers were tested initially with one strain each from all Dickeya spp., except for D. solani and D. zeae, for which two and three strains were tested, respectively. No amplification was observed in negative controls that lacked template DNA or contained $P$. carotovorum subsp. carotovorum DNA. An additional 30 Dickeya strains were tested; all strains tested had observable positive results (Table 1). Therefore, a threshold for reactions determined as positive was based on the amplification of 40 Dickey $a$ strains and set at $30 \mathrm{~min}$. Primer specificity was tested with an additional 44 strains, including Pectobacterium spp., Clavibacter spp.,Acidovorax avenae, Brenneria spp., and other plant-associated or nontarget organisms. The LAMP assay did not react positively with any nonDickeya strains or with the negative controls.

Sensitivity of the LAMP assay. In a series of 10-fold dilutions starting with DNA at $1 \mathrm{ng} / \mu \mathrm{l}$, the detection limit for an observable result was DNA at approximately $5 \mathrm{pg} /$ reaction. At this reduced concentration of DNA, a shift in time was observed for a positive reaction; approximately $40 \mathrm{~min} /$ reaction was needed for an observable positive result. However, single colonies isolated from cultures grown on plates or crude extracts prepared from diseased tissue should contain an ample quantity of bacterial cells to provide enough DNA to fall within the threshold of $30 \mathrm{~min}$ for a positive reaction.

TABLE 3. GenBank accession numbers for strains used in phylogenetic analysis

\begin{tabular}{|c|c|c|c|}
\hline Number ${ }^{\mathrm{a}}$ & Strain ID & Organism & GenBank ID \\
\hline A5415 & CFBP $2048^{\mathrm{T}}$ & $\begin{array}{l}\text { Dickeya chrysanthemi biovar } \\
\text { chrysanthemi }\end{array}$ & JX434861.1 \\
\hline A5574 & IPO 2117 & D. chrysanthemi biovar parthenii & JX434870.1 \\
\hline A5641 & CFBP 1270 & D. chrysanthemi biovar parthenii & JX434879.1 \\
\hline A5416 & CFBP $1269^{\mathrm{T}}$ & Dickeya dadantii subsp. dadantii & JX434862.1 \\
\hline A5642 & CFBP 3855 & D. dadantii subsp. dadantii & JX434880.1 \\
\hline A5643 & CFBP 6467 & D. dadantii subsp. dadantii & JX434881.1 \\
\hline A5419 & CFBP 2051 & $\begin{array}{l}\text { Dickeya dadantii subsp. } \\
\text { dieffenbachiae }\end{array}$ & JX434865.1 \\
\hline A5578 & IPO 2124 & $\begin{array}{l}\text { D. dadantii subsp. } \\
\text { dieffenbachiae }\end{array}$ & JX434871.1 \\
\hline A5646 & CFBP 3694 & $\begin{array}{l}\text { D. dadantii subsp. } \\
\text { dieffenbachiae }\end{array}$ & JX434884.1 \\
\hline A5418 & CFBP $1200^{\mathrm{T}}$ & Dickeya dianthicola & JX434864.1 \\
\hline A5571 & IPO 1741 & D. dianthicola & JX434887.1 \\
\hline A5644 & CFBP 2015 & D. dianthicola & JX434882.1 \\
\hline A5645 & CFBP 4155 & D. dianthicola & JX434883.1 \\
\hline A5420 & CFBP $4178^{\mathrm{T}}$ & Dickeya paradisiaca & JX434866.1 \\
\hline A5579 & IPO 2127 & D. paradisiaca & JX434872.1 \\
\hline A5581 & IPO 2187 & Dickeya solani & JX434888.1 \\
\hline A5582 & IPO 2188 & D. solani & JX434889.1 \\
\hline A5422 & CFBP $2052^{\mathrm{T}}$ & Dickeya zeae & JX434868.1 \\
\hline A5423 & CFBP 6466 & D. zeae & JX434869.1 \\
\hline A5647 & CFBP 1531 & D. zeae & JX434885.1 \\
\hline A5421 & CFBP 1272 & Dickeya sp. & JX434867.1 \\
\hline \multirow[t]{2}{*}{ A5417 } & CFBP 1278 & Dickeya sp. & JX434863.1 \\
\hline & Et1/99 & Erwinia tasmaniensis & CU468135.1 \\
\hline
\end{tabular}

a Acquisition number from the Alvarez laboratory at the University of Hawai' $\mathrm{i}$ at Mānoa.

TABLE 2. Loop-mediated isothermal amplification primers developed for the detection of Dickeya spp.

\begin{tabular}{|c|c|c|}
\hline $\begin{array}{l}\text { Oligonucleotide } \\
\text { primer }\end{array}$ & Sequence $\left(5^{\prime}-3^{\prime}\right)^{\mathrm{a}}$ & $\begin{array}{l}\text { Source, } \\
\text { reference }\end{array}$ \\
\hline $\mathrm{MglC}-\mathrm{F} 3$ & TCGCTATCGGCGGTAACC & This study \\
\hline $\mathrm{MglC}-\mathrm{B} 3$ & ACCACCGGCAAAAGACAC & This study \\
\hline MglC-FIP & GCCGGACAGCATATACACCCAAGGAAGCCGCCAAAGTGTC & This study \\
\hline MglC-BIP & CCTTCGGCGGTATGCTGGAAGCGATGGCGTCAAGTTCGTA & This study \\
\hline MglC-Loop & CGGTAGTGCCACTAACAACCTGG & This study \\
\hline MglC-Loop probe & /56-FAM/ACGCTGAGGACCCGGATGCGAATGCGGATGCGGATGCCGATTTTCGGTAGTGCCACTAACAACCTGG & This study \\
\hline Quencher probe & TCGGCATCCGCATCCGCATTCGCATCCGGGTCCTCAGCGT/3BHQ_1/ & $\begin{array}{l}\text { Kubota } \\
\text { et al. } 2011\end{array}$ \\
\hline
\end{tabular}

a Abbreviations: /56-FAM/ = 5'6-carboxyfluorescein, /3BHQ_1/ = 3' black hole quencher 1, and /5IABkFQ/ = 5' Iowa Black FQ. 
In mixed cultures containing increasing amounts of DNA from the closely related pathogen $P$. carotovorum subsp. carotovorum, the detection limit of the LAMP reaction was not affected. All samples, including a combined mixture of $100 \mathrm{ng}$ of Dickeya and Pectobacterium DNA, were positive, showing that LAMP could be reliably used without a loss in sensitivity or inhibition due to contaminant DNA, even at high concentrations.

Evaluation of the Dickeya LAMP assay from plant tissue samples. LAMP reliably amplified Dickeya DNA in the absence of time-consuming preparatory steps, such as pure culture isolation or purified DNA extraction, after infected tissue sampling. Direct addition of crude lysate from infected pineapple or potato tissue had no observable impact on amplification. Presence of the pathogen was verified from the infected pineapple tissue by direct plating, followed by confirmation via amplification with two separate conventional PCR and sequencing of the dnaA marker. Amplification by the $d n a A$ primers and phylogenetic analyses with other isolates of Dickeya confirmed the identity of the pineapple isolate A6174 as a Dickeya sp. (Fig. 2). This strain clustered with two other strains (CFBP 1278 and CFBP 1282) that were originally isolated from plants showing pineapple heart rot in Malaysia (Samson et al. 2005). Amplification was not detected with this primer set when
Dickeya DNA was absent from the sample preparation (i.e., healthyplant controls and sterile-water control).

Potato inoculated with $D$. solani strain IPO 2187 showed typical symptoms of tissue maceration 2 days postinoculation. No dilutions were necessary to detect the pathogen from inoculated plant extracts, whereas no amplification was observed from the waterinoculated control or negative controls. On average, amplification was observed within 15 to $25 \mathrm{~min}$.

\section{DISCUSSION}

Detection of Dickeya spp. is challenging due to the genetic heterogeneity observed among strains, along with the complex nature of the pathogens; multiple species are known to cause similar symptoms on one host, and a single species can infect multiple hosts (Samson et al. 2005). Detection and identification of Dickeya spp. can be further complicated by its environmental proximity on overlapping hosts to closely related pathogens such as Pectobacterium spp. For example, under warm, wet conditions, symptoms of blackleg and soft rot in potato are markedly similar, whether caused by Pectobacterium or Dickeya spp., thus making identification of the causal agent impossible by visual inspection alone. Several molecular

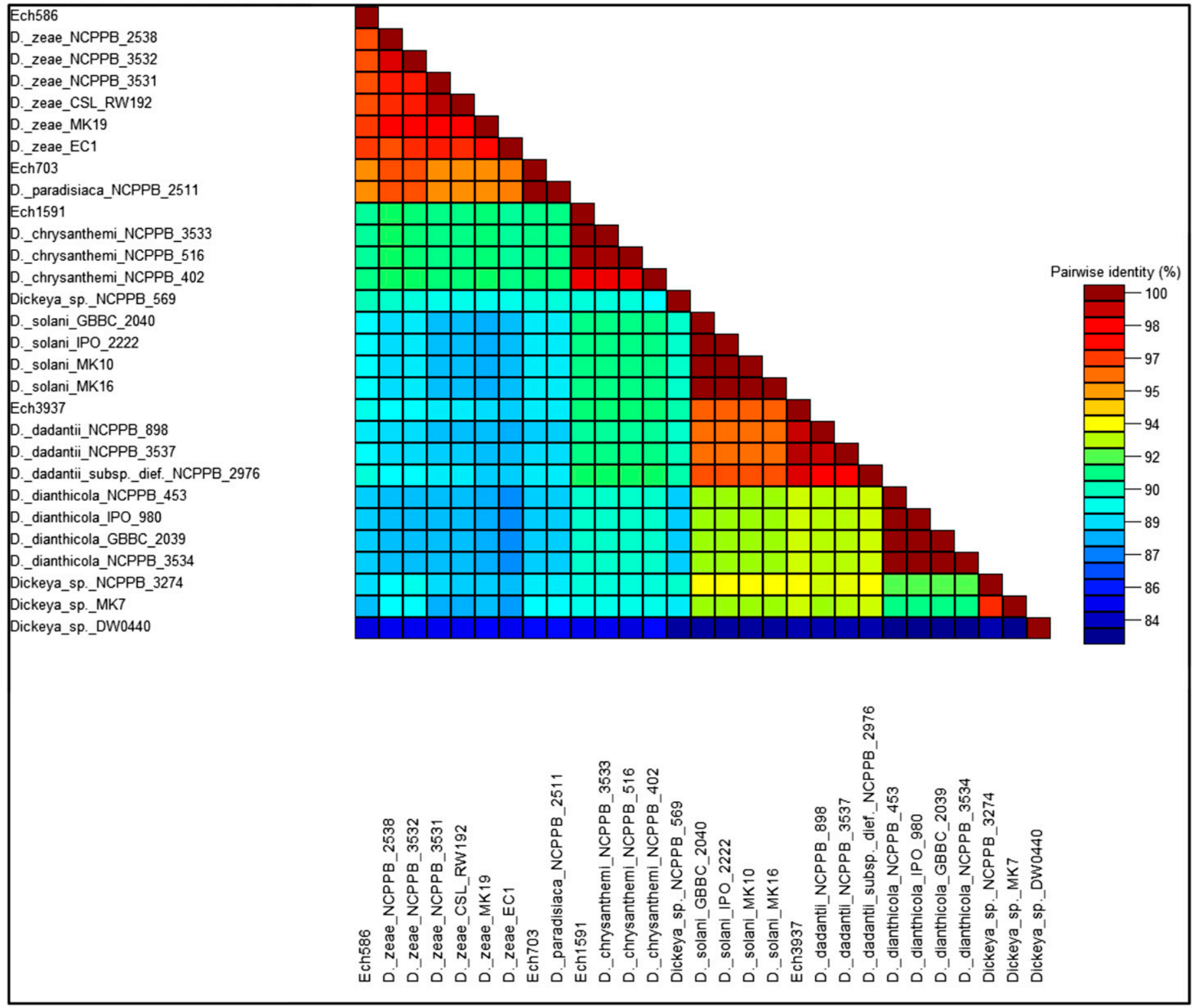

Fig. 1. Color-coded matrix displaying pairwise identity scores between the $m g l C$ gene sequences of Dickeya spp. 
amplification methods and procedures have been developed in order to detect Dickeya spp. or distinguish them from Pectobacterium spp. (Diallo et al. 2009; Laurila et al. 2010; Pritchard et al. 2013; van der Wolf et al. 2014a; Van Vaerenbergh et al. 2012). Nucleic acid-based assays are available for the detection of Dickeya spp., including a multiplex PCR (Diallo et al. 2009) and real-time quantitative (q)PCR (Laurila et al. 2010) assay; however, these methods were not tested against $D$. zeae or $D$. paradisiaca and D. paradisiaca (Laurila et al. 2010), respectively. Species-level TaqMan qPCR assays have been developed to detect individual Dickeya spp. (van der Wolf et al. 2014a; Van Vaerenbergh et al. 2012) but cross-reactivity was observed, demonstrating reduced specificity.

In this study, LAMP primers designed to target a region of the $m g l C$ gene had broader detection ability for Dickeya spp. than nucleic-acid methods described previously, which may be more advantageous in testing regimes where more than one Dickeya sp. may be present on a host such as potato. This broader detection ability also presents no disadvantages for detection where only a given species (i.e., D. solani or D. dianthicola) may be the target pathogen of interest for seed certification programs.

Relative to conventional PCR and other PCR-based methods, the LAMP assay is rapid, requires lower equipment costs, obviates the need for highly skilled personnel, and can be used without the need for time-consuming DNA extraction procedures. In samples prepared from crude extracts of infected pineapple suspected of harboring Dickeya spp. and Dickeya-inoculated potato, positive results were observed upon simple bacterial diffusion from the infected tissue, followed by a boil step. This is in contrast to some assays that require the use of an enrichment step prior to analysis for the detection of Dickeya (de Haan and van den Bovenkamp 2009).
Further optimization of the DNA extraction method may be required for different sample types; however, LAMP has been shown to be less sensitive overall to plant inhibitors (phenolic compounds) (M. Arif, unpublished information).

The $m g l C$ LAMP primers designed in this study led to specific amplification of the 40 strains of Dickeya spp. tested. Additionally, the presence of a high amount of competitor or contaminant DNA in the reaction tube (P. carotovorum subsp. carotovorum) had no effect on the specific amplification of Dickeya DNA and resulted in no concomitant loss in sensitivity. The presence of competitor DNA did not reduce the detection limit of the LAMP assay, therefore showing the good overall specificity and high sensitivity of the assay. The LAMP assay developed in this study was assessed on two different plant samples: a naturally infected pineapple from the field and a lab-inoculated potato sample. The LAMP assay was able to detect Dickeya spp. in the infected pineapple tissue, while showing negative results in healthy-looking pineapple tissue. Bacteria were isolated from the diseased tissue and confirmed to be Dickeya spp. by pelADE (Nassar et al. 1996) and dnaA (Marrero et al. 2013; Schneider et al. 2011) PCR analysis. The genus Dickeya was also detected from diseased potato tissue while showing negative results in control potato tissue. The LAMP assay was able to detect Dickeya spp. in these plant tissues with minimal sample preparation. Plant samples were simply macerated or soaked in water to allow bacteria to diffuse into suspension and then boiled at $95^{\circ} \mathrm{C}$ for $10 \mathrm{~min}$.

The specificity and sensitivity of this assay demonstrates its utility as a specific test for detecting Dickeya sp. Moreover, this assay is suitable for field tests due to the simplicity of sample preparation and the portability of the LAMP assay using hand-held real-time amplification technologies. Additionally, the gene target used for detection has application across several molecular detection platforms

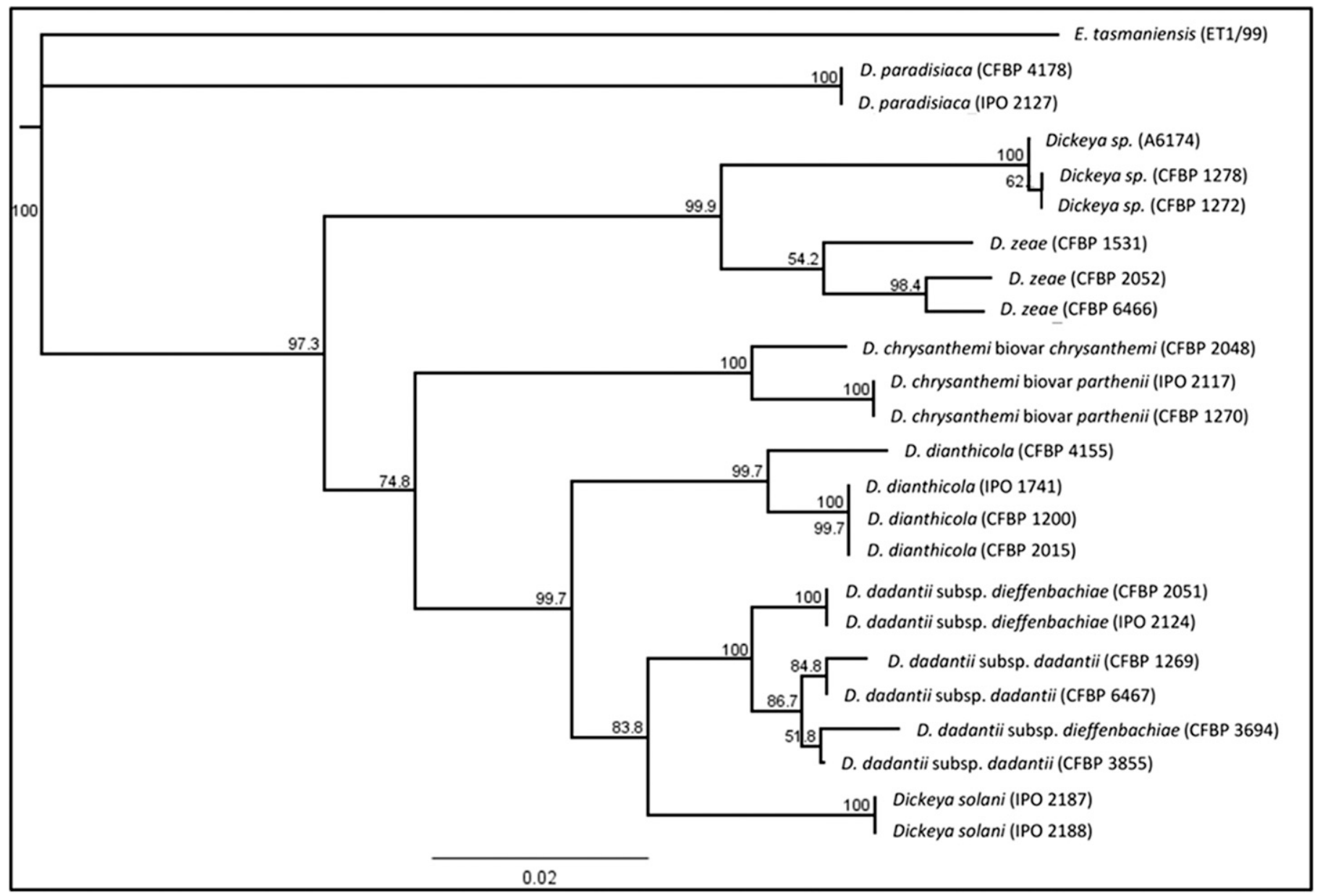

Fig. 2. Phylogenetic analysis of the pineapple field-sample strain A6174 dnaA gene. 
such as PCR, nicking-enzyme amplification reaction (Maples et al. 2009a,b; Van Ness et al. 2003), and recombinase polymerase amplification (Piepenburg et al. 2006).

\section{ACKNOWLEDGMENTS}

This work was supported by the United States Department of Agriculture National Institute of Food and Agriculture Hatch project HAW00987-H and the University of Hawaii Foundation-Plant Disease Control fund 120-50604.

\section{LITERATURE CITED}

Czajkowski, R., Pérombelon, M. C. M., Jafra, S., Lojkowska, E., Potrykus, M., van der Wolf, J. M., and Sledz, W. 2015. Detection, identification and differentiation of Pectobacterium and Dickeya species causing potato blackleg and tuber soft rot: A review. Ann. Appl. Biol. 166:18-38.

de Haan, E. G., and van den Bovenkamp, G. W. 2009. Test development in Erwinia at the NAK: BioPlex real-time PCR. Gewasbescherming 40:172-175.

Diallo, S., Latour, X., Groboillot, A., Smadja, B., Copin, P., Orange, N., Feuilloley, M. G. J., and Chevalier, S. 2009. Simultaneous and selective detection of two major soft rot pathogens of potato: Pectobacterium atrosepticum (Erwinia carotovora subsp. atrosepticum) and Dickeya spp. (Erwinia chrysanthemi). Eur. J. Plant Pathol. 125:349-354.

Felsenstein, J. 1985. Confidence limits on phylogenies: An approach using the bootstrap. Evolution 39:783-791.

Gardan, L., Gouy, C., Christen, R., and Samson, R. 2003. Elevation of three subspecies of Pectobacterium carotovorum to species level: Pectobacterium atrosepticum sp. nov., Pectobacterium betavasculorum sp. nov. and Pectobacterium wasabiae sp. nov. Int. J. Syst. Evol. Microbiol. 53:381-391.

Humphris, S., Cahill, G., Elphinstone, J. G., Kelly, R., Parkinson, N. M., Pritchard, L., Toth, I. K., and Saddler, G. S. 2015. Detection of the bacterial potato pathogens Pectobacterium and Dickeya spp. using conventional and real-time PCR. Pages 1-16 in: Plant Pathology: Techniques and Protocols. C. Lacomme, ed. Methods in Molecular Biology, Vol. 1302. Springer Science+Business Media, New York.

Jukes, T. H., and Cantor, C. R. 1969. Evolution of protein molecules. Pages 21-132 in: Mammalian Protein Metabolism. H. N. Munro, ed. Academic Press, New York.

Kaneshiro, W. S., Burger, M., Vine, B. G., de Silva, A. S., and Alvarez, A. M. 2008. Characterization of Erwinia chrysanthemi from a bacterial heart rot of pineapple outbreak in Hawaii. Plant Dis. 92:1444-1450.

Kearse, M., Moir, R., Wilson, A., Stones-Havas, S., Cheung, M., Sturrock, S., Buxton, S., Cooper, A., Markowitz, S., Duran, C., Thierer, T., Ashton, B., Mentjies, P., and Drummond, A. 2012. Geneious Basic: An integrated and extendable desktop software platform for the organization and analysis of sequence data. Bioinformatics 28:1647-1649.

Kubota, R., Alvarez, A. M., Su, W. W., and Jenkins, D. M. 2011. FRET-based assimilating probe for sequence-specific real-time monitoring of loopmediated isothermal amplification (LAMP). Biol. Eng. Trans. 4:81-100.

Laurila, J., Hannukkala, A., Nykyri, J., Pasanen, M., Hélias, V., Garlant, L., and Pirhonen, M. 2010. Symptoms and yield reduction caused by Dickeya spp. strains isolated from potato and river water in Finland. Eur. J. Plant Pathol. 126:249-262.

Li, X., Nie, J., Ward, L. J., Nickerson, J., and de Boer, S. H. 2011. Development and evaluation of a loop-mediated isothermal amplification assay for the rapid detection and identification of Pectobacterium atrosepticum. Can. J. Plant Pathol. 33:447-457.

Ma, B., Hibbing, M. E., Kim, H.-S., Reedy, R. M., Yedidia, I., Breuer, J., Breuer, J., Glasner, J. D., Perna, N. T., Kelman, A., and Charkowski, A. O. 2007. Host range and molecular phylogenies of the soft rot enterobacterial genera Pectobacterium and Dickeya. Phytopathology 97:1150-1163.

Maples, B. K., Holmberg, R. C., Miller, A. P., Provins, J. W., Roth, R. B., and Mandell, J. G. 2009a. United States of America Patent No. US 2009/0081670 A1.

Maples, B. K., Holmberg, R. C., Miller, A. P., Provins, J. W., Roth, R. B., and Mandell, J. G. 2009b. United States of America Patent No. US 2009/0017453 A1.

Marrero, G., Schneider, K. L., Jenkins, D. M., and Alvarez, A. M. 2013. Phylogeny and classification of Dickeya based on multilocus sequence analysis. Int. J. Syst. Evol. Microbiol. 63:3524-3539.
Muhire, B. M., Varsani, A., and Martin, D. P. 2014. SDT: A virus classification tool based on pairwise sequence alignment and identity calculation. PLoS One 9:e108277.

Nagamine, K., Hase, T., and Notomi, T. 2002. Accelerated reaction by loopmediated isothermal amplification reaction using loop primers. Mol. Cell. Probes 16:223-229.

Nagamine, K., Watanabe, K., Ohtsuka, K., Hase, T., and Notomi, T. 2001. Loop-mediated isothermal reaction using a nondenatured template. Clin. Chem. 47:1742-1743.

Nassar, A., Darrasse, A., Lemattre, M., Kotoujansky, A., Dervin, C., Vedel, R., and Bertheau, Y. 1996. Characterization of Erwinia chrysanthemi by pectinolytic isozyme polymorphism and restriction fragment length polymorphism analysis of PCR-amplified fragments of pel genes. Appl. Environ. Microbiol. 62:2228-2235.

Ngadze, E., Coutinho, T. A., and van der Waals, J. E. 2010. First report of soft rot of potatoes caused by Dickeya dadantii in Zimbabwe. Plant Dis. 94:1263.

Notomi, T., Okayama, H., Masubuchi, H., Yonekawa, T., Watanabe, K., Amino, N., and Hase, T. 2000. Loop-mediated isothermal amplification of DNA. Nucleic Acids Res. 28:e63.

Piepenburg, O., Williams, C. H., Stemple, D. L., and Armes, N. A. 2006. DNA detection using recombination proteins. PLoS Biol. 4:e204.

Pritchard, L., Glover, R. H., Humphris, S., Elphinstone, J. G., and Toth, I. K. 2016. Genomics and taxonomy in diagnostics for food security: Soft-rotting enterobacterial plant pathogens. Anal. Methods 8:12-24.

Pritchard, L., Humphris, S., Saddler, G. S., Parkinson, N. M., Bertrand, V., and Elphinstone, J. G. 2013. Detection of phytopathogens of the genus Dickeya using a PCR primer prediction pipeline for draft bacterial genome sequences. Plant Pathol. 62:587-596.

Saitou, N., and Nei, M. 1987. The neighbor-joining method: A new method for reconstructing phylogenetic trees. Mol. Biol. Evol. 4:406-425.

Samson, R., Legendre, J. B., Christen, R., Fischer-Le Saux, M., Achouak, W., and Gardan, L. 2005. Transfer of Pectobacterium chrysanthemi (Burkholder et al. 1953) Brenner et al. 1973 and Brenneria paradisiaca to the genus Dickeya gen. nov. as Dickeya chrysanthemi comb. nov. and Dickeya paradisiaca comb. nov. and delineation of four novel species, Dickeya dadantii sp. nov., Dickeya dianthicola sp. nov., Dickeya dieffenbachiae sp. nov. and Dickeya zeae sp. nov. Int. J. Syst. Evol. Microbiol. 55:1415-1427.

Schneider, K. L., Marrero, G., Alvarez, A. M., and Presting, G. G. 2011. Classification of plant associated bacteria using RIF, a computationally derived DNA marker. PLoS One 6:e18496.

Tamura, K., Dudley, J., Nei, M., and Kumar, S. 2007. MEGA 4: Molecular evolutionary genetics analysis (MEGA) software version 4.0. Mol. Biol. Evol. 24:1596-1599.

Toth, I. K., van der Wolf, J. M., Saddler, G., Lojkowska, E., Hélias, V., Pirhonen, M., Tsror (Lahkim), L., and Elphinstone, J. G. 2011. Dickeya species: An emerging problem for potato production in Europe. Plant Pathol. 60:385-399.

van der Wolf, J. M., de Haas, B. H., van Hoof, R., de Haan, E. G., and van den Bovenkamp, G. W. 2014a. Development and evaluation of Taqman assays for the differentiation of Dickeya (sub)species. Eur. J. Plant Pathol. 138:695-709.

van der Wolf, J. M., Nijhuis, E. H., Kowalewska, M. J., Saddler, G. S., Parkinson, N., Elphinstone, J. G., Pritchard, L., Toth, I. K., Lojkowska, E., Potrykus, M., Waleron, M., de Vos, P., Cleenwerck, I., Pirhonen, M., Garlant, L., Hélias, V., Pothier, J. F., Pflüger, V., Duffy, B., Tsror, L., and Manulis, S. 2014b. Dickeya solani sp. nov., a pectinolytic plant-pathogenic bacterium isolated from potato (Solanum tuberosum). Int. J. Syst. Evol. Microbiol. 64:768-774.

Van Ness, J., Van Ness, L. K., and Galas, D. J. 2003. Isothermal reactions for the amplification of oligonucleotides. Proc. Natl. Acad. Sci. USA 100: 4504-4509.

Van Vaerenbergh, J., Baeyen, S., De Vos, P., and Maes, M. 2012. Sequence diversity on the Dickeya fliC gene: Phylogeny of the Dickeya genus and TaqMan ${ }^{\circledR}$ PCR for ' $D$. solani', new biovar variant on potato in Europe. PLoS One 7:e35738.

Yasuhara-Bell, J., Marrero, G., De Silva, A., and Alvarez, A. M. 2016. Specific detection of Pectobacterium carotovorum by loop-mediated isothermal amplification. Mol. Plant Pathol. 17:1499-1505. 